УДК 37.015.31

\author{
ФОРМИРОВАНИЕ ПРОФЕССИОНАЛЬНОЙ НАПРАВЛЕННОСТИ \\ КУРСАНТОВ ВОЕННЫХ ВУЗОВ \\ С.Г. Марковчин, И.М. Садыков
}

\begin{abstract}
Марковчин Сергей Григорьевич, кандидат технических наук, начальник, Новосибирское высшее военное командное училище, Новосибирск, Россия. E-mail: vivat91@mail.ru
\end{abstract}

Садыков Ильфат Мухарлямович, заместитель начальника, Новосибирское высшее военное командное училище, Новосибирск, Россия. E-mail: imsadykov@mail.ru

\begin{abstract}
Аннотация. $B$ статье анализируется сущность, содержание и возможность современной войны, и необходимость для военных специалистов высокой военно-профессиональной направленности для успешного решения профессиональных задач. Анализируются основные подходы, существующие в российской педагогической и психологической науках, $к$ определению сущности и содержания профессиональной направленности. Определена специфика этого понятия в военной психологии и военной педагогике. Исследованьл факторы, влияющие на формирование военно-профессиональной направленности курсантов военных вузов. Показана необходимость учета в профессиональном воспитании будущих офичеров современных сочиальных условий и особенностей российской молодежи. Результаты проведенного исследования позволили сделать авторам следующее заключение о том, что работа по формированию духовно-цеенностных основ, повычение благосостояния офицеров и их семей, откровенное представление современных угроз России, делают формирование военно-профессиональной направленности курсантов военных вузов более успешным. Повышение эффрективности формирования военнопрофессиональной направленности у курсантов военных вузов организуется в современных условиях в системе военно-политической работы. Ценностными основами военнопрофессиональной направленности будущих офицеров, являются идея патриотизма $u$ исторически сложившиеся смыслы и иенности российского офицерства, исторический $u$ современный опыт военно-профессиональной деятельности российских военных специиалистов в мирное время и боевой обстановке.
\end{abstract}

Ключевые слова: профессиональная направленность, военно-профессиональная направленность курсантов, необходимость формирования профессиональной направленности. 


\title{
FORMATION OF PROFESSIONAL DIRECTIONS OF COURSES OF MILITARY UNIVERSITIES
}

S.G. Markovchin, I.M. Sadykov

\author{
Sergey G. Markovchin, \\ Candidate of Technical Sciences, Head of the Novosibirsk \\ Higher Military Command School, Novosibirsk, Russian Federation. \\ E-mail: vivat91@mail.ru \\ Ilfat M. Sadykov, \\ Deputy Head of the Novosibirsk Higher Military \\ Command School, Novosibirsk, Russian Federation. \\ E-mail: vivat91@mail.ru
}

\begin{abstract}
The article analyzes the essence, content and possibility of modern war and the need for military specialists of high military-professional orientation to successfully solve professional problems. The main approaches that exist in the Russian pedagogical and psychological sciences to the definition of the essence and content of a professional orientation are analyzed. The specificity of this concept in military psychology and military pedagogy has been determined. The factors influencing the formation of the military-professional orientation of cadets of military universities are investigated. The necessity of taking into account the modern social conditions and characteristics of Russian youth in the professional education of future officers is shown. The results of the study allowed the authors to draw the following conclusion that the work on the formation of spiritual and value foundations, the improvement of the well-being of officers and their families, a frank presentation of modern threats to Russia, make the formation of a militaryprofessional orientation of cadets of military universities more successful. An increase in the effectiveness of the formation of a military-professional orientation among cadets of military universities is organized in modern conditions in the system of military-political work. The value foundations of the military professional orientation of future officers are the idea of patriotism and the historically formed meanings and values of Russian officers, the historical and modern experience of the military professional activities of Russian military specialists in peacetime and in a combat situation.
\end{abstract}

Keywords: professional orientation, military-professional orientation of cadets, the need to form a professional orientation.

Обоснование проблемы исследования. Современные военные конфликты, как свидетельствуют события последних десятилетий, не повторяют сущностно, содержательно, по форме и методам ведения конфликты прошлого столетия. Между тем, в современном сознании общества, как впрочем и в профессиональном мнении кадровых военных, поскольку армия - часть общества, распространены представления о Мировой войне на основе опыта предшествующей, проходившей в 1939-1945 гг.

Идущая сегодня гибридная война, в которой пока преобладают «невоенные» средства противоборства, увеличивает опасность новой мировой войны. Сегодня достаточно сложно определить, какой по счету она будет.

Очевидно, что несмотря на то, что россияне считают последней Мировой войной ту, в которой наша страна одержала победу - Великую Отечественную, была другая, в которой разгромлен СССР и его союзники. По масштабам этого разгрома экономические потери 
нашей страны, утрата территорий, населения и политического влияния в мире были существенно большими.

Это и была Третья мировая, «холодная», информационно-психологическая война. Ее внешняя картина безусловно не соответствовала событиям Второй мировой войны, а основные средства ее ведения (экономические, информационно-психологические, привлекательные в молодежной среде культура, мода, музыка, феномен сексуальной раскрепощенности и т.п.) сделали ее незаметной. Только после окончания конфликтов в «горячих» точках бывшего СССР и ревизии экономических потерь (высокотехнологичных отраслей промышленности, науки здравоохранения и сельского хозяйства стало ясно Третья мировая война закончилась, ее окончанию сопутствовала уже новая геополитическая реальность. Об этом свидетельствует и тот факт, что в США руководство государственных институтов и состав силовых структур были награждены медалями «За победу в холодной войне».

Небольшим по времени был и «предвоенный» период, после которого, уже в 2001 году, после падения зданий Всемирного торгового центра в Нью-Йорке, государственный секретарь США К. Райс и директор ЦРУ Д. Вулси объявили о том, что США вступает в Четвертую мировую войну и будет вести ее до победы.

И эта война имеет новый облик. В отличие от предшествующих, на поле боя действуют повстанческо-партизанские, или откровенно бандитские формирования, либо не имеющие четкой государственной идентификации организации современных наемников (частные военные кампании). Вместе с этим, они получают финансирование и высокотехнологичную поддержку со стороны развитых государств Запада, а войну ведут с вооруженными силами государств, имеющих неразвитую экономику и неспособных обеспечить их современными силами вооруженной борьбы [15, с. 282-297].

Таким образом, все вышеобозначенное делает проблему эффективного формирования профессиональной направленности курсантов военных вузов весьма актуальной для России, её обороноспособности.

Теоретико-методологические основы исследования составили научные концепции, научные положения и теории, известных отечественных исследователей и специалистов военного дела (А.В. Барабанщикова, Н.Ф. Феденко, А.К. Быков, Л.В. Мардахаев, Г.Д. Луков, В.И. Лутовинов А.Д. Лопуха, Б.П. Бархаев, А.Г. Караяни, В.Ф. Перевалов, И.В. Сыромятников, Попов И.М., Хамзатов М.М. др.). Настоящее исследование носит аналитический характер. Использовались методы исследования: теоретические (анализ, синтез, сравнение, сопоставление и обобщения научной литературы по проблеме исследования); эмпирические (беседа, интервью, экспертная оценка).

Обсуждение результатов исследования. В подготовке офицеров Вооруженных Сил РФ в системе военного образования таким образом необходимо обеспечить формирование компетенций, позволяющих решать разнонаправленные задачи.

В условиях роста числа военных угроз России все больше военных специалистов становятся участниками реальных боевых действий.

Это требует от них сформированности профессиональной направленности, эмоционально-волевой готовности к предстоящей профессиональной деятельности. Речь идет о том, что мотивация и направленность личности выпускника военного вуза должны обеспечивать выполнение задач в мирное и военное время.

Каковы сущность и содержание профессиональной направленности офицера, как военного специалиста? 
Толковый словарь русского языка определяет направленность как «целеустремленную сосредоточенность на чем-нибудь мыслей, интересов». В данном случае, речь идет о направленности лица «занимающегося чем-нибудь, как профессией». ${ }^{1}$

В педагогике и психологии профессиональная направленность трактуется по-разному. Так, например, Л.Б. Нурмухаметова и её коллеги считает, что «профессиональная направленность - это интегральная характеристика мотивации профессиональной деятельности, определяемая всеми побуждениями в мотивационной сфере и в особой мере выражающаяся в интересах, отношениях, целенаправленных усилиях» [12, с. 94-95].

Л.И. Кунц полагает, что «под направленностью следует понимать совокупность мотивов, ориентирующих личность в поведении, деятельности и общении, то профессиональная направленность будет отражать побудительную сторону профессиональной деятельности» [10, с. 138].

А.Н. Котухов и А.А. Моисеев считают, что «под профессиональной направленностью мы можем понимать внутреннюю предрасположенность, мотивацию, способности, склонности и задатки субъекта к конкретной профессиональной деятельности. Это совокупность индивидуальных свойств личности, её черт, качеств, ценностных ориентаций, взглядов, и побуждений, а также совокупность профессиональных притязаний, характерных для соответствующей деятельности и готовность применения указанных компонентов в процессе выполнения должностных обязанностей» [8, с. 184].

В словаре Н.Е. Дружинина по профориентации и психологической поддержке «Профессиональная направленность - это интегральная характеристика мотивации профессиональной деятельности, определяемая всеми побуждениями в мотивационной сфере и в особой мере выражающаяся в интересах, отношениях, целенаправленных усилиях». ${ }^{2}$

Более полно определение дает О.И. Пец. Профессиональная направленность понимается ей, прежде всего, как «совокупность мотивационных образований (интересов, потребностей, склонностей, стремлений и др.), связанных с профессиональной деятельностью человека и влияющих, в частности, на выбор профессии, стремление работать по ней и удовлетворенность профессиональной деятельностью. Профессиональная направленность представляет собой интегральное образование и характеризуется предметом профессиональной направленности, в качестве которого выступает предпочитаемая профессия (вид деятельности); видами мотивов профессиональной деятельности; силой (уровнем) направленности, проявляющейся в степени выраженности стремления к овладению профессией и работе по ней; знаком, выражающимся в удовлетворенностинеудовлетворенности человека своей профессией» [14, с. 36].

Таким образом, с одной стороны, профессиональная направленность (как и направленность личности) характеризуется проявлением мотивационных образований (установки, потребности, цели, ценности, смыслы и т.д.). С другой стороны, профессиональная направленность обладает своей особой спецификой и определяется, прежде всего, отношением личности к профессии, к себе как специалисту, а также профессиональными компетенциями, социально-профессиональным статусом, эмоционально-волевой готовностью, пр.

\footnotetext{
1 Ожегов С.И., Шведова Н.Ю. Толковый словарь русского языка. 4-е изд., РАН. Москва: ООО «ИТИ технологии», 2006. - 944 с.

${ }^{2}$ Словарь по профориентации и психологической поддержке / Сост. Н.Е. Дружинин. Кемерово-Томск, 2003.

URL: https://career_counseling_support.academic.ru/363/Профессиональная направленность.
} 
Проблема военно-профессиональной направленности личности военнослужащего, ее сущность и характеристики исследуются в работах отечественных военных ученых. Они относят военно-профессиональную направленность к важным качествам офицеров.

Известный А.В. Барабанщиков профессиональную направленность называет ведущим компонентом структуры личности офицера, обеспечивающим высокую эффективность его служебной деятельности [13].

М.П. Коробейников считает, что направленность личности (потребности и мотивы, их осознанность, сила и степень развития) занимает важнейшее место среди субъективных условий, от которых, наряду с объективными обстоятельствами, зависит тип ведущей деятельности военнослужащего [10].

По мнению Н.Ф. Феденко, направленность выражается системой «целей, стоящих перед человеком, целей, которые он преследует своими действиями» [7].

К.В. Синицын считает военно-профессиональную направленность наиболее значимым для офицера свойством личности, представляющим собой основанную на государственно-патриотическом мировоззрении, внутренне согласованную, устойчивую систему осознанных потребностей, побуждений, целей, перспектив, стремлений и активных отношений к овладению профессией и совершенствованию в ней [20].

В.Л. Разгонов считает [19], что военно-профессиональная направленность может рассматриваться как сложное, интегративное свойство личности, включающее преобладающие мотивы, потребности, интересы, жизненные цели, склонности, убеждения, идеалы и ценностные ориентации, проявляемые как положительное отношение к военнопрофессиональной деятельности, активное стремление к овладению профессией офицера и совершенствованию в ней.

Сформированная устойчивая военно-профессиональная направленность является важным условием успешности военно-профессионального воспитания курсантов. Он считает, что структура военно-профессиональной направленности личности отражает структуру общей направленности личности и в соответствии с системным подходом может быть представлена совокупностью четырех взаимообусловленных компонентов, придающих воспитанию курсантов успешность и одновременно в ходе него развивающихся:

- мотивационно-ценностный компонент включает направленность на объект военнопрофессиональной деятельности; преобладающие мотивы, потребности, склонности, выражающиеся в увлеченности военно-профессиональной деятельностью (либо одним из ее видов); осознание ее цели, общественной значимости и необходимости; признание ценностью овладение офицерской деятельностью; профессиональные планы;

- гносеологический компонент объединяет знания содержания и условий деятельности по избранной военной профессии, правильные представления о требованиях профессии к психофизиологическим и личностным качествам человека, а также совокупность представлений о себе как субъекте военно-профессиональной деятельности;

- эмоционально-оценочный компонент отражает эмоциональное отношение к избранной офицерской профессии; проявляется в удовлетворенности военнопрофессиональной деятельностью, склонности заниматься ею и добиваться успешности в деятельности;

- деятельностный компонент включает осознание своих способностей к офицерской деятельности, своего уровня военно-профессиональной компетенции; устойчивую мотивацию на самосовершенствование с целью развития необходимых для служебной деятельности профессионально важных качеств.

Взаимосвязь и взаимообусловленность компонентов военно-профессиональной направленности отражаются в следующем. Мотивы, интересы влияют на степень активности личности, побуждают человека заниматься избранной воинской профессией, что, в свою 
очередь, способствует укреплению мотивации, дальнейшему развитию интересов, установок, профессионально важных качеств личности. Соответствие психофизиологических и личностных качеств требованиям избранной военной профессии, увлеченность ею, возможность реализовать в ней свои потребности позволяют обеспечить высокие служебные показатели, успешность в офицерской профессии. Это влечет за собой удовлетворенность избранной профессией и стремление заниматься ею, совершенствовать свои способности и компетенции, желание связать свои жизненные планы с профессией офицера [19, с. 143].

Важная роль в формировании военно-профессиональной направленности принадлежит воинской среде формирования личности, характеру воспитания и обучения в военном вузе.

Во многих учебниках и учебных пособиях по военному делу отмечается, что направленность теснейшим образом связана с мировоззрением, историко-экономическими и социальными условиями жизни (общественный и государственный строй, господствующие в данном обществе нормы морали, уровень развития культуры). Так Г.Д. Луков подчеркивает решающую роль патриотизма, политической сознательности, составляющих ядро направленности личности офицера, определяющих мотивы его поведения в мирной и боевой обстановке. ${ }^{3}$

Н.Ф. Феденко выделяет основные группы мотивов выбора профессии офицера:

1. Мотивы, детерминируемые общими социальными условиями: осознание необходимости приносить пользу обществу, желание оказывать помощь людям, общественная установка на необходимость деятельности.

2. Мотивы, детерминируемые специфическими условиями профессиональной деятельности.

3. Мотивы, определяемые непосредственно особенностями характера самой личности: удовлетворение потребности в самоактуализации, самовыражении, самореализации.

4. Мотивы, связанные с условиями материального характера: получение определенных материальных благ для себя и семьи [2].

Курсант, выступая субъектом воинского труда, стремится к достижению профессионализма в том случае, когда у него сильны мотивы профессиональных достижений и профессиональной самореализации. С военно-профессиональной направленностью его личности, субъективными отношениями к военнослужебной деятельности тесно связано развитие профессионально значимых качеств личности будущего офицера в ходе дальнейшей службы.

Военно-профессиональная направленность личности курсанта - это интегративное свойство личности, активно-действенное отношение к офицерской профессиональной деятельности и важное условие профессионального воспитания будущих офицеров российской армии при обучении в военном вузе.

Многие специалисты военного дела считают, что основной целью воспитания курсантов определены формирование и развитие качеств и отношений гражданина-патриота, военного профессионала и высоконравственной и разносторонне развитой личности. Формирование направленности курсантов на ее достижение - одна из важнейших задач военного образования (И.А. Алехин, А.Д. Лопуха, В.Л. Разгонов, др.).

По мнению современных военных психологов «формирование профессионального опыта - сложный и длительный процесс. В его образовании задействованы как внутренние, так и внешние факторы. В числе факторов, которые несет сама профессия, как род занятий включает:

- систему технологических норм и способов деятельности;

\footnotetext{
${ }^{3}$ Луков Г.Д. Основы военной психологии: учебное пособие. - М.: Воениздат, 1964. - 344 с.
} 
- систему социальных связей и отношений с «кооперантами» [1, с. 226].

Формирование профессиональной направленности курсантов военного вуза осуществляется в процессе воспитания, проводимого непосредственно в условиях военной службы. Его направленность и содержание жестко определены нормативно-правовыми документами, регулирующими требованиями к качествам будущих офицеров, определяющих порядок учебной и служебной деятельности. Существенно влияет на формирование профессиональной направленности обучающихся пример и профессиональный опыт командно-педагогического состава ввузов, коллег по учебе.

В формировании военно-профессиональной направленности $\mathrm{y}$ курсантов и слушателей военных вузов, которую определяли как ведущее психологическое свойство обучающихся военных вузов, представляющее систему внутренних побуждений и жизненных целей ученые Военно-политической академии им. В.И. Ленина во главе с А.В. Барабанщиковым [17, с. 73-80] так определяли его содержание. Движущей силой формирования военно-профессиональной направленности определялись потребности будущих офицеров в обретении этого статуса. При этом, важнейшей задачей было формирование их мировоззрения, военно-политических и профессиональных убеждений. На их основе формировались профессиональный интерес, склонность к офицерской профессии, которые позволяли формирование военно-профессиональных идеалов, жизненных стратегий, включающих профессиональные цели, установки и перспективы.

Такой подход безусловно обеспечивал формирование профессиональной направленности курсантов в советский период. Первое постсоветское десятилетие было связано с утратой ряда инструментов эффективного воздействия в профессиональном воспитании будущих офицеров. Это относится к утрате его идейно-ценностных основ, снижении престижности офицерской профессии, оборонного сознания россиян, росту аморализма и меркантилизации социальных отношений.

Пик проблем военного образования пришелся на период руководства Вооруженными Силами А.Э. Сердюкова. С приходом к руководству Министерством обороны РФ С.К. Шойгу ситуация стала выправляться. Работа по формированию духовно-ценностных основ, повышение благосостояния офицеров и их семей, откровенное представление современных угроз России делают формирование военно-профессиональной направленности курсантов военных вузов более успешным. Вместе с этим, в ней необходим учет глубоких изменений, происходящих в молодежной среде (нарастание меркантильности, снижение коллективистской ориентации, рост индивидуализма и других негативных проявлений) [3, с. 51-59].

Заключение. Таким образом, результаты проведенного исследования позволяют утверждать, что сегодня в сложных современных условиях существования мирового сообщества, существует необходимость повышения эффективности формирования военнопрофессиональной направленности у российских курсантов военных вузов в системе военнополитической работы России. Важнейшими основами эффективности формирования военнопрофессиональной направленности у курсантов военных вузов, являются идея патриотизма, исторически сложившиеся ценности российского офицерства, включая исторический и современный опыт военно-профессиональной деятельности военных специалистов в мирное время и боевой обстановке.

\section{Литература:}

1. Бархаев Б.П., Караяни А.Г., Перевалов В.Ф., Сыромятников И.В. Психология и педагогика профессиональной деятельности офицера. - М.: Воениздат, 2006. - 488 с.

2. Богомолов А.Н. Показатели педагогической готовности выпускников вузов войск национальной гвардии Российской Федерации // ЦИТИСЭ. - 2020. - № 1 (23). - С. 206215. DOI: http://doi.org/10.15350/24097616.2020.1.19 
3. Гуслякова Л.Г., Говорухина Г.В. Трансформация смысложизненных ориентаций молодежи (2003-2013 гг.) // Образование и социальное развитие региона. - 2014. № 1. - С. 51-59.

4. Егорычев А.М., Мардахаев Л.В., Ахтян А.Г., Шимановская Я.В. Основы гражданственности и патриотизма в истории нашего Отечества // ЦИТИСЭ. - 2019. - №4 (21). C. 467- 476. DOI: http://doi.org/10.15350/24097616.2019.4.44

5. Карчакин А.Н. Особенности социализации личности в условиях военнопрофессиональной среды // Мир науки, культуры и образования. - 2020. - № 2(81). - С. 240242. URL: https://www.elibrary.ru/item.asp?id=42837045

6. Клименко П.В. Интеграция традиций и инноваций как ресурс патриотического воспитания курсантов военного вуза. Диссертация на соиск. уч. ст. канд. пед. наук: 13.00.01 общая педагогика, история педагогики и образования. - Краснодар: КГУ, 2020. - 215 с.

7. Коробейников М.П. Современный бой и проблемы психологии. - М.: Воениздат, 1972. - 235 с.

8. Котухов А.Н., Моисеев А.А. Профессиональная направленность: сущность и структура // Молодой ученый. - 2017. - № 12 (146). - С. 182-190.

9. Кротова М.Н. О специфике индивидуально-психологических особенностей курсантов военного вуза на начальном этапе профессионализации // Вопросы теории и методики профессионального образования. - Ярославль: Ярославский государственный педагогический университет им. К.Д. Ушинского, 2018. - С. 143 - 147. URL: https://www.elibrary.ru/item.asp?id=35677768

10. Кунц Л.И. Профессиональная направленность и направленность личности // Сибирский педагогический журнал. - 2013. - №4. - C. 137-140. URL: https://www.elibrary.ru/item.asp?id=20171962

11. Лутовинов В.И. Формирование уважения к прошлому и любви к Отечеству в процессе изучения истории в системе среднего образования // Актуальные проблемы современного образования: опыт и инновации: матер. всероссийской научно-практической конф. с дистанционным и международным участием / Отв. Ред. А.Ю. Нагорнова. Ульяновск: Изд-во «Зебра», 2019. https://www.elibrary.ru/item.asp?id=41890344

12. Нурмухаметова Л.Б., Салаватова Г.Р., Бильданова В.Р. Профессиональная направленность студентов // Международный журнал экспериментального образования. 2014. - № 6-1. - C. 94-95. URL: https://www.elibrary.ru/item.asp?id=21477249

13. Основы военной психологии и педагогики: учеб. пособие / под ред. А.В. Барабанщикова, Н.Ф. Феденко. - М.: Воениздат, 1981. - 366 с.

14. Пец О.И. Профессиональная направленность личности // Современная наука. 2014. - № 1. - C. 35-41. URL: https://www.elibrary.ru/item.asp?id=25923617

15. Попов И.М., Хамзатов М.М. Война будущего: Концептуальные основы и практические выводы. Очерки стратегической мысли. - М.: Кучково поле, 2016. - 832 с.

16. Примаков В.Л. Социализация офицера в условиях военной службы: на примере Вооруженных Сил Российской Федерации. Дис. ... д-ра. соц. наук: 22.00.08. - М., 2000. - 391 c.

17. Профессиональное образование в России: вызовы, состояние, направления развития: коллективная монография / А.М. Егорычев, Л.В. Мардахаев, В.В. Сизикова, Т.К. Ростовская и др.; под ред. А.М. Егорычева. - М.: Изд-во РГСУ, 2019. - С. 152-188. URL: https://www.elibrary.ru/item.asp?id=41222164

18. Психология и педагогика высшей военной школы / под ред. А.В. Барабанщикова. - М.: Воениздат, 1989. - 366 с. 
19. Разгонов В.Л. Военно-профессиональное воспитание курсантов военных вузов и их профессиональная направленность // Гуманитарные проблемы военного дела. - 2015. № 3 (4). - C. 140-143. URL: https://www.elibrary.ru/item.asp?id=25597438

20. Синицын К.В. Формирование военно-профессиональной направленности у курсантов военных вузов РВСН в современных условиях: автореф. дис. на соиск. уч. степ. канд. психол. наук: 20.02.02. - М., 2004. - 28 с.

21. Утюганов А.А. Система ценностно-смысловых ориентаций курсантов вузов национальной гвардии: феноменология и психолого-педагогические детерминанты формирования. Диссертация на соиск. уч. ст. док. псих. наук: 19.00.07 - педагогическая психология. - Кемерово: КГУ, 2019. - 401 с.

\section{References:}

1. Barhaev B.P., Karayani A.G., Perevalov V.F., Syromyatnikov I.V. Psychology and pedagogy of the officer's professional activity. Moscow, Military Publ., 2006, 488 p. (In Russian)

2. Bogomolov A.N. Indicators of pedagogical readiness of graduates of universities of the troops of the National Guard of the Russian Federation. CITISE, 2020, no. 1 (23), pp. 206-215. (In Russian) DOI: http://doi.org/10.15350/24097616.2020.1.19

3. Guslyakova L.G., Govorukhina G.V. Transformation of the life-meaning orientations of youth (2003-2013). Education and social development of the region, 2014, no. 1, pp. 51-59. (In Russian)

4. Egorychev A.M., Mardakhaev L.V., Akhtyan A.G., Shimanovskaya Ya.V. Fundamentals of civic consciousness and patriotism in the history of our Fatherland. CITISE, 2019, no. 4 (21), pp. 467- 476. (In Russian) DOI: http://doi.org/10.15350/24097616.2019.4.44

5. Karchakin A.N. Features of socialization of the individual in a military-professional environment. World of Science, Culture and Education, 2020, no. 2 (81), pp. 240-242. (In Russian) URL: https://www.elibrary.ru/item.asp?id=42837045

6. Klimenko P.V. Integration of traditions and innovations as a resource of patriotic education of cadets of a military university. Krasnodar, KSU Publ., 2020, 215 p. (In Russian)

7. Korobeinikov M.P. Modern combat and problems of psychology. Moscow, Military Publ., 1972, 235 p. (In Russian)

8. Kotukhov A.N., Moiseev A.A. Professional orientation: essence and structure. Young scientist. 2017, no. 12 (146), pp. 182-190. (In Russian)

9. Krotova M.N. On the specifics of individual psychological characteristics of cadets of a military university at the initial stage of professionalization. Yaroslavl, Yaroslavl State Pedagogical University. K. D. Ushinsky Publ., 2018, no. S, pp. 143 - 147. (In Russian) URL: https://www.elibrary.ru/item.asp?id=35677768

10. Kunts L.I. Professional orientation and personality orientation. Siberian pedagogical journal, 2013, no. 4, pp. 137-140. (In Russian) URL: https://www.elibrary.ru/item.asp?id=20171962

11. Lutovinov V.I. Formation of respect for the past and love for the Fatherland in the process of studying history in the secondary education system. Ulyanovsk, "Zebra" Publ., 2019, pp. 147-151. (In Russian) URL: https://www.elibrary.ru/item.asp?id=41890344

12. Nurmukhametova L.B., Salavatova G.R., Bildanova V.R. Professional orientation of students. International Journal of Experimental Education, 2014, no. 6-1, pp. 94-95. (In Russian) URL: https://www.elibrary.ru/item.asp?id=21477249

13. Barabanshchikova A.V., Fedenko N.F. Basics of military psychology and pedagogy. Moscow, Military Publ., 1981, 366 p. (In Russian)

14. Pec O.I. Professional orientation of the personality. Modern science. 2014, no. 1, pp, 35-41. (In Russian) URL: https://www.elibrary.ru/item.asp?id=25923617 
15. Popov I.M., Khamzatov M.M. War of the Future: Conceptual Framework and Practical Conclusions. Essays on strategic thought. Moscow, Kuchkovo field Publ., 2016, 832 p. (In Russian)

16. Primakov V.L. Socialization of an officer in the conditions of military service: on the example of the Armed Forces of the Russian Federation. Moscow, 2000, 391 p. (In Russian)

17. Egorychev A.M., Mardakhaev L.V., Professional education in Russia: challenges, state, development directions. Monograph. Moscow, Russian State Social University Publ., 2019, pp. 152-188. (In Russian) URL: https://elibrary.ru/item.asp?id=41222164

18. Drumbshchikova A.V. Psychology and pedagogy of the higher military school. Moscow, Voenizdat Publ., 1989, 366 p. (In Russian)

19. Razgonov V.L. Military-professional education of cadets of military universities and their professional orientation. Humanitarian problems of military affairs, 2015, no. 3 (4), pp. 140143. (In Russian) URL: https://www.elibrary.ru/item.asp?id=25597438

20. Sinitsyn K. V. Formation of a military-professional orientation among cadets of military universities of the Strategic Missile Forces in modern conditions. Moscow, 2004, 28 p. (In Russian)

21. Utyuganov A.A. The system of value-semantic orientations of cadets of higher educational institutions of the National Guard: phenomenology and psychological-pedagogical determinants of formation. Kemerovo, KSU Publ., 2019, 401 p. (In Russian)

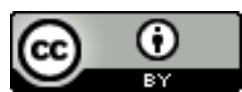

